\title{
On Nepali Translation of Hemingway's The Old Man and the Sea: The Analysis of Translation Strategies
}

SUDESH MANGER

\begin{abstract}
The present paper is an attempt to explore the translation of The Old Man and the Sea, by Khagendra Mani Pradhan in 2010 and, by Sanjiv Upadhay in the same year, 2010. The paper discusses the two translation strategies and methodologies adopted by both translators in a similar sociocultural, political, and historical context, and how both the translations present The Old Man and the Sea uniquely within Nepali Polysystem. Hence, it emphasizes the function and role of translation in a Polysystem, that is relatively new and trying to incorporate or express the contemporary socio-political context through the medium of literature.
\end{abstract}

Keywords: Nepali Literature, Translation Studies, Translated Literature and Translation Strategies.

\section{Introduction}

The influence of English literature has been one of the most important facets of the history of Nepali literature. Translation has played an instrumental role in bringing such influence to Nepali polysystem ${ }^{1}$. The translations of English texts have been instrumental in enriching the existing literature and brought freshness by ushering in new genres like novels and short stories. The early Nepali literary system was dominated

\footnotetext{
${ }^{1}$ Translated literature not only as an integral system within any literary polysystem, but also as a most active system within it. But what is its position within the polysystem, and how is this position connected with the nature of its overall repertoire (Zohar 2012:163).
} 
by Kavya (Poetry) from the time of Bhanubhakta Acharya's ${ }^{2}$ translation of the Ramayana until the 1940s. From 1940 onwards, there was a sort of craze among the writers to explore new genres, novels (Upaniyas) and short stories (katha). The writers like Manjushree Thapa (1968-present), Parijat (Bishnu Kumari Waiba) (1937-93), Bhim Nidhi Tiwari (1911-73) Indra Bahadur Rai (1927-Present), and many others from both Nepal and India have contributed a lot as a short story writer or a novelist.

The general notion that the original writing is ipso facto superior to translation, such claim would be difficult to make when it comes to Nepali literature. Right from the beginning of written literature until the contemporary scenario, translation has played an instrumental role in the development of literature.

The present paper explores the subsequent translation strategies adopted by the two different translators in different historical and cultural contexts and how the two translators coordinate the relationship between different systems. At the same time, to build the trajectory of the role played by translation in the formation of Nepali literature, this study undertakes recourse to the English translation of Ernest Hemmingway's The Old Man and the Sea (1952), 'the story of an epic struggle between an old, seasoned fisherman and the greatest catch of his life'. It is a masterpiece of Ernest Hemingway, published in 1952 was awarded the Pulitzer Prize for Literature in the same year and the Nobel Prize for literature in 1954.

\footnotetext{
${ }^{2}$ Bhanubhakta Acharya (1814-1868) was a Nepali poet, translator, and writer. He was the first writer to translate the great epic Ramayana from Sanskrit to Nepali.
} 
In an interview with George Plimpton, Hemingway said his satisfaction in what he considered to be the aesthetic economy of the novel:

The Old Man and the Sea could have been over a thousand pages long and had every character in the village in it and all the processes of the way they made their living were born, educated, bore children, etc. That is done excellently and well by other writers. In writing, you are limited by what has already been done satisfactorily. Therefore, I have tried to learn to do something else. First, I have tried to eliminate everything unnecessary to conveying experience to the reader so that after he or she has read something it will become part of his or her experience and seem actually to have happened. This is very hard to do and I have worked at it very hard (Bloom 2008: 1).

In the last decade, several translations of The Old Man and the Sea has appeared in the Nepali language by Okiyama Gwayne's Budho ra Samudra (1969), Khagendra Mani Pradhan's Budho ra Samudra (2010), Sanjiv Upadhay's Budho Manche ra Sagar (2010), Hom Kumar Shrestha's Budo Majhi Ra Samundra (2015), Anestra Hamingua's Budo Manxe Ra Samundra (2016) and Trishna D. Kaudinya's Budo Manche Ra Samundra (2018). Hom Kumar Shrestha has also provided the audio version of the text; it was narrated by Achyut Ghimire Bulbul in Shrutisambeg (Broadcasting) in 2015. Another audio version of the text in Nepali was released on youtube by Krishna Aryal on Nov 9, 2016.

However, the paper takes recourse to the translation of Khagendra Mani Pradhan as Budho ra Samudra and Sanjiv Upadhay as Budho Manche ra Sagar. Both the translations had two different groups of readers, one who is familiar with American literature and the other, ignorant of it. 
Sanjiv has used the 'domesticating ${ }^{3}$ method to address the readers who are not aware of the American way of writing. He has translated most of the words using colloquial jargon. In a way, it helps the readers read and understand the text as it was originally written in Nepali. Khagendra has translated the text using the method of 'foreignizing', which is to address the elite readers who are aware of American history. He has retained most of the English words as they are in Hemingway's novel. A comparative study of the two translations and their English source text is undertaken here to analyze the various translational methods employed by both Nepali translators.

The different translations of Ernest Hemmingway's The Old Man and the Sea. These two translations were done by Khagendra Mani Pradhan as Budho ra Samudra and Sanjiv Upadhay as Budho Manche ra Sagar - both the translations appeared in 2010. In a way, it is an act of rereading the same text in another language. By translating this novel into Nepali, Khagendra Mani acknowledges the role of the novel in the other literature and assumes that it will have the same impact on Nepali literature through translation. He says:

Bishwa Sahitya nirmanma ye kriti le kasta Bhumika kheleko thiyo ra bishwa sthar kriti liye samay chet au bunouto shilpa kasro hunu parcha, thes disa tira yes anuwad karya le hami lekhakharu liye sayog dine cha bhanne kura pati hami asha wadi chow (Pradhan 2010: I).

The text has played a major role for the development of world literature and has provided the method of writing a masterpiece. Considering this factor, I hope the translation will

\footnotetext{
${ }^{3}$ An ethnocentric reduction of the foreign text to dominant cultural values (Venuti, 2008, pg 68).

${ }^{4}$ an ethnodeviant pressure on those values to register the linguistic and cultural differences of the foreign text (Venuti 2008: 68).
} 
help writers in Nepali literature to reach a similar level of writings (Translation is mine).

Translation is an act of rewriting and recreating the same magic through translation in a new language becomes the biggest challenge for the translator, which is neatly explained by Sujit Mukherjee as follows:

Reading for translation may be placed at the highest level because not only must the translator interpret the text reasonably, but he must also restructure his interpretation in another language while striving to approximate the original structure (Mukherjee 1997: 141).

The act of translation is to conglomerate two distinct cultures in a language that is the mixture of both the source and target culture. The danger involved in mixing the two languages is hardly seen by the readers who only try to find fault with the translation by highlighting the source elements that are missing in the translation. However, in the Nepali translation of The Old Man and the Sea by two Nepali translators, the translators have been very careful in paying attention to all the nitty-gritty of the source culture and have brought it with similar charm in the target language. The description of the old man in the English and Nepali versions read with the same kind of vitality as can be observed from the following:

Everything about him was old except his eyes and they were the same color as the sea and were cheerful and undefeated (Hemingway 1956: 4).

Akhan bahek uska sabai angha haru budho hudai ayeka thiye bhane ti akhanharu chaie sagar ko pani jastai thiea, khusi thiea ani aparajit pane (Upadhay 2010: 11).

Apart from his eyes, all the parts of his body were old; his eyes looked like the sea, happy and unbeatable (Translation is mine). 
Unka bare ma bhanu parda akhan bahek aru sabai purana thiea, jun akhan ko rang samudra jastai ani sadhai uthsapurna ra aparajit (Pradhan 2010: 4).

To describe him, every part of his body was old except his eyes, which were like the sea, and every time it was cheerful and unbeatable (Translation is mine).

The theme of Honor in Struggle, Defeat, and Death is well maintained in Nepali translation by not changing the concepts of the novel. They tried to describe the situation in a way that can be associated with the situation of any poor man who struggles in everyday life for survival. Hemingway creates a symbolic parallel between Santiago and Christ. When Santiago's palms are first cut by his fishing line, the reader cannot help but think of Christ suffering his stigmata. Later, when the sharks arrive, Hemingway portrays the old man as a crucified martyr, saying that he makes a noise like that of a man having nails driven through his hands. Furthermore, the image of the old man struggling up the hill with his mast across his shoulders recalls Christ's march toward Calvary.

The description of Old man's hand in Nepali with the biblical note, and usage of some words from the Bible like, 'Christ', 'Mother Marry', as 'Yasu' and 'Mariam Mata' corresponds with the English novel. In a way, it does not tamper with the symbolism of Hemingway. In their usage of language, to maintain the standard of English the translators have used the everyday language and replaced certain words which have equivalent words in Nepali like 'Salao' by 'alachene', 'boat' by 'Dhungra'. By giving the regional flavor to the foreign concepts, the translator Sanjiv has taken care of his readers who are not aware of the Spanish words like 'salao'. Similarly, considering the other groups of readers, Khagendra has retained some English words and in the case of some others, he 
has given the English words in brackets like 'Tigers of Detroit', 'stew', 'Hatuey Beer', 'Casablanca', 'Dock' etc.

The translation of this canon not only brings the American concept and Nobel Prize-winning novella into Nepali literature but also tries to revive or revisit the Nepali canon. For instance, Muna-Madan (Nepali episodic love poem published in 1936 by the poet Laxmi Prasad Devkota) also deals with the impact of materialistic life in a small household, where the protagonist goes to Tibet to earn money for the better future of his wife Muna and his old mother, but at the end, he returns home without money only to find his wife and mother dead like Santiago who struggles for "eighty-four days" but ends with few carcasses or no fish. Despite the continuous failure for eighty-four days, Santiago is optimistic about the future and wants to be prepared for the opportunity, he says:

Only I have no luck anymore. But who knows? Maybe today. Every day is a new day. It is better to be lucky. But I would rather be exact. Then luck comes you are ready (Hemingway 1956: 22).

Yati ho, Hijoaja mero bhagyale alik sath diyeko chaina. Tara kaslai thach? Huna sakcha Aja. Pratayek din ayuta naya din huncha. Bhagyamani hunu nai ramro. Tara moh sahi nai rahana chanchu. Taki bhagyale sath dida tayar rahos (Pradhan 2010: 25).

Aaja pani Bhagya udyouna sakcha. Prateek din nai auta naya din ho. Yo din arubhanda bhagyashali pani huna sakcha. Ani hunu nai ramro. Tes bela panim moh thik nai rahane chu. Jaba saubhagya aucha tyetikher prastut hunu parcha (Upadhay 2010: 30).

The concept of opportunity and optimism presented by Hemingway has been translated uniquely by Khagendra and Sanjeev. Khagendra starts with the negative connotation by 
saying 'the luck has not favored me these days', but it can be different today, whereas Sanjeev starts with the positive connotation, 'I might be lucky today'. The technique adopted by both the translators might be different, however, it reflects on the condition of the then-contemporary Nepali society, where the condition of youth or old is dim. The restlessness amongst the citizen for a better future is well represented by passage. The concept of opportunity and optimism, that is somehow missing needs to reverberate and find hope within the surroundings, rather than evading it.

The choice of the works to be translated and the goals of the translational activity are set by certain forces. In its intellectual aspect, translation as a means of cultural enrichment has always played a crucial role in Nepali literature. Hence translation takes the form of rewriting an original text and it is performed under certain constraints and for certain purposes. The original text is chosen for a certain purpose and the guidelines of translation are defined to serve this purpose by the translator and/or by those who initiate the translation activity. In this case, rewriting to fit the purpose, along with fidelity to the original text, becomes the main issue for the translator.

\section{Conclusion}

Incorporating foreign material in Nepali literature does involve certain constraints. The incorporation of an alien theme of concept, far from the ground reality can alienate the reader. Apart from that, the reader's response to the new form of writings matters a lot to the writers who incorporate the new methods. In the Indian context, Sujit Mukherjee rightly observes the situation of readers, who are least interested in reading Indian texts in the following lines:

Likely, they do not read any Indian writings, either because they receive greater satisfaction from reading foreign authors 
or because they cannot read any Indian language well enough to be able to respond to literature composed in their language (Mukherjee 1997: 133).

By translating the English texts into Nepali, the translated text can enrich the existing literature and expand the horizon of various approaches in Nepali literature. The aspects of realism, existentialism, modernism, romanticism, and translation of canonical texts brought the newness in the writings of the Nepali authors who were earlier following only a particular trend of Bhakti and Bhir Dhara (Nepali Literary movements) for more than a century. It was a sort of push that helped them to set free from the clutches of the traditional writers and focus on the prevalent social-cultural, economic, political, and human issues in their writings. Therefore, the immense contribution of translation for the growth of Nepali literature remains insurmountable for generations to come. The popularity of these writings based on the borrowed materials from the English writers has also paved the way for others to imitate these models and as a result, Nepali literature has seen, for instance, the development of women writers.

\section{References}

ANDERSON, JON AARUM. 2016. An Old Man and the "Sea of Leadership". Journal of Leadership Studies: Expanding Interdisciplinary Discourse 9(4). 70-81. https://doi.org/10.1002/jls.21422.

BASSNET, SUSAN. 2002. Translation Studies. London and New York: Routledge.

BLOOM, HAROLD (ed.). 2008. Bloom's Modern Critical Interpretations: Ernest Hemingway's The Old Man and the Sea. New York: Infobase Publishing.

DAHAL, RAJKUMARI. 2010. Anuvad Vimarsh (Discourse on Translation). Siliguri: Pratima Prakshan. 
HEDIGER, RYAN. 2008. Hunting, Fishing, and the Cramp of Ethics in Ernest Hemingway's The Old Man and the Sea, Green Hills of Africa, and Under Kilimanjaro. The Hemingway Review 27(2). 35-59. Doi:10.1353/hem.0.0011. PRADHAN, KHAGENDRA MANI. (Trans). 2010. Budho ra Samudra (The Old Man and the Sea). Sikkim: Sikkim Academy.

UPADHAY, SANJIV. (Trans). 2010. Budho Manche ra Sagar (The Old Man and the Sea). Assam: Nutun Sahitya Parishad.

HEMMINGWAY, ERNEST. 1952. The Old Man and the Sea. United Kingdom: Arrow Books.

HUTT, MICHAEL. 1991. Himalayan Voices: An Introduction to

Nepali Literature. Oxford: University of California Press. HUTT, MICHAEL. 1997. Modern Literary Nepali: An Introductory Reader. Delhi: Oxford University Press. HUTT, MICHAEL. 1998. Nepali: A National Language and its Literature. New Delhi: Sterling Publishers. ITAMAR, EVEN-ZOHAR. 2002. The Position of Translated Literature within the Literary Polysystem. In Lawrence, Venuti (ed.), The Translation Studies Reader. New York: Routledge.

MANGER, SUDESH. 2012. The Role of Translation in the Formation of Nepali Literary Culture. Hyderabad: The English and Foreign Languages University Dissertation. MUKHERJEE, SUJIT. 1981. Translation as Discovery and Other Essays on Indian Literature in English Translation. New Delhi: Allied Publishers.

MUNDAY, JEREMY. 2008. Introducing Translation Studies:

Theories and Applications. New York: Routledge.

SHRESTHA, DAYARAM \& MOHAN RAJ SHARMA. 1999. Nepali

Sahityako Samchhipta Itihas (A Brief History of Nepali Literature). Darjeeling: Sajahn Prakashan. 
On Nepali Translation of Hemingway's The Old Man and the Sea:...

SHRESTA, DAYARAM. 2008. Sahitya ko Itihas: Sidhanta ra

Sandhrva (History of Literature: Theory and context).

Kathmandu: Paluwa Prakashan

VENUTI, LAWRENCE. 2008. The Translator's Invisibility: A

History of Translation. USA and Canada: Routledge. NIDA, EUGENE. 2002. Principles of Correspondence. In

Lawrence Venuti (ed.), The Translation Studies Reader. New York: Routledge.

Cite This Work:

MANGER, SudESH. 2021. On Nepali Translation of Hemingway's The Old Man and the Sea: The Analysis of Translation Strategies. Translation Today, Vol. 15(1). 169179. DOI:10.46623/tt/2021.15.1.no1 